\title{
Validity of a self-administered food frequency questionnaire (FFQ) and its generalizability to the estimation of dietary folate intake in Japan
}

\author{
Junko Ishihara ${ }^{1,2}$, Seiichiro Yamamoto ${ }^{3}$, Hiroyasu Iso ${ }^{2,4}$, Manami Inoue ${ }^{1}$, \\ Shoichiro Tsugane*1 and the JPHC FFQ Validation Study Group
}

Address: ${ }^{1}$ Epidemiology and Prevention Division, Research Center for Cancer Prevention and Screening, National Cancer Center, 5-1-1 Tsukiji, Chuo-ku, Tokyo, 104-0051 Japan, ${ }^{2}$ Department of Public Health Medicine, Majors of Medical Sciences, Graduated School of Comprehensive Medical Sciences, University of Tsukuba, Ibaraki, Japan, ${ }^{3}$ Statistics and Cancer Control Division, Research Center for Cancer Prevention and Screening, National Cancer Center, Tokyo, Japan and ${ }^{4}$ Public Health, Department of Social and Environmental Medicine, Graduate School of Medicine, Osaka University, Osaka, Japan

Email: Junko Ishihara - junishih@gan2.ncc.go.jp; Seiichiro Yamamoto - siyamamo@gan2.ncc.go.jp;

Hiroyasu Iso - fvgh5640@mb.infoweb.ne.jp; Manami Inoue - mnminoue@gan2.res.ncc.go.jp; Shoichiro Tsugane* - stsugane@ncc.go.jp

* Corresponding author

Published: 05 October 2005

Nutrition Journal 2005, 4:26 doi:10.1186/1475-289/-4-26
Received: 12 July 2005

Accepted: 05 October 2005

This article is available from: http://www.nutritionj.com/content/4/I/26

(C) 2005 Ishihara et al; licensee BioMed Central Ltd.

This is an Open Access article distributed under the terms of the Creative Commons Attribution License (http://creativecommons.org/licenses/by/2.0), which permits unrestricted use, distribution, and reproduction in any medium, provided the original work is properly cited.

\begin{abstract}
Background: In an epidemiological study, it is essential to test the validity of the food frequency questionnaire (FFQ) for its ability to estimate dietary intake. The objectives of our study were to I) validate a FFQ for estimating folate intake, and to identify the foods that contribute to interindividual variation of folate intake in the Japanese population.

Methods: Validity of the FFQ was evaluated using 28-day weighed dietary records (DRs) as gold standard in the two groups independently. In the group for which the FFQ was developed, validity was evaluated by Spearman's correlation coefficients (CCs), and linear regression analysis was used to identify foods with large inter-individual variation. The cumulative mean intake of these foods was compared with total intake estimated by the DR. The external validity of the FFQ and intake from foods on the same list were evaluated in the other group to verify generalizability. Subjects were a subsample from the Japan Public Health Center-based prospective Study who volunteered to participate in the FFQ validation study.
\end{abstract}

Results: CCs for the internal validity of the FFQ were 0.49 for men and 0.29 and women, while CCs for external validity were 0.33 for men and 0.42 for women. CCs for cumulative folate intake from 33 foods selected by regression analysis were also applicable to an external population.

Conclusion: Our FFQ was valid for and generalizable to the estimation of folate intake. Foods identified as predictors of inter-individual variation in folate intake were also generalizable in Japanese populations. The FFQ with 138 foods was valid for the estimation of folate intake, while that with 33 foods might be useful for estimating inter-individual variation and ranking of individual folate intake. 


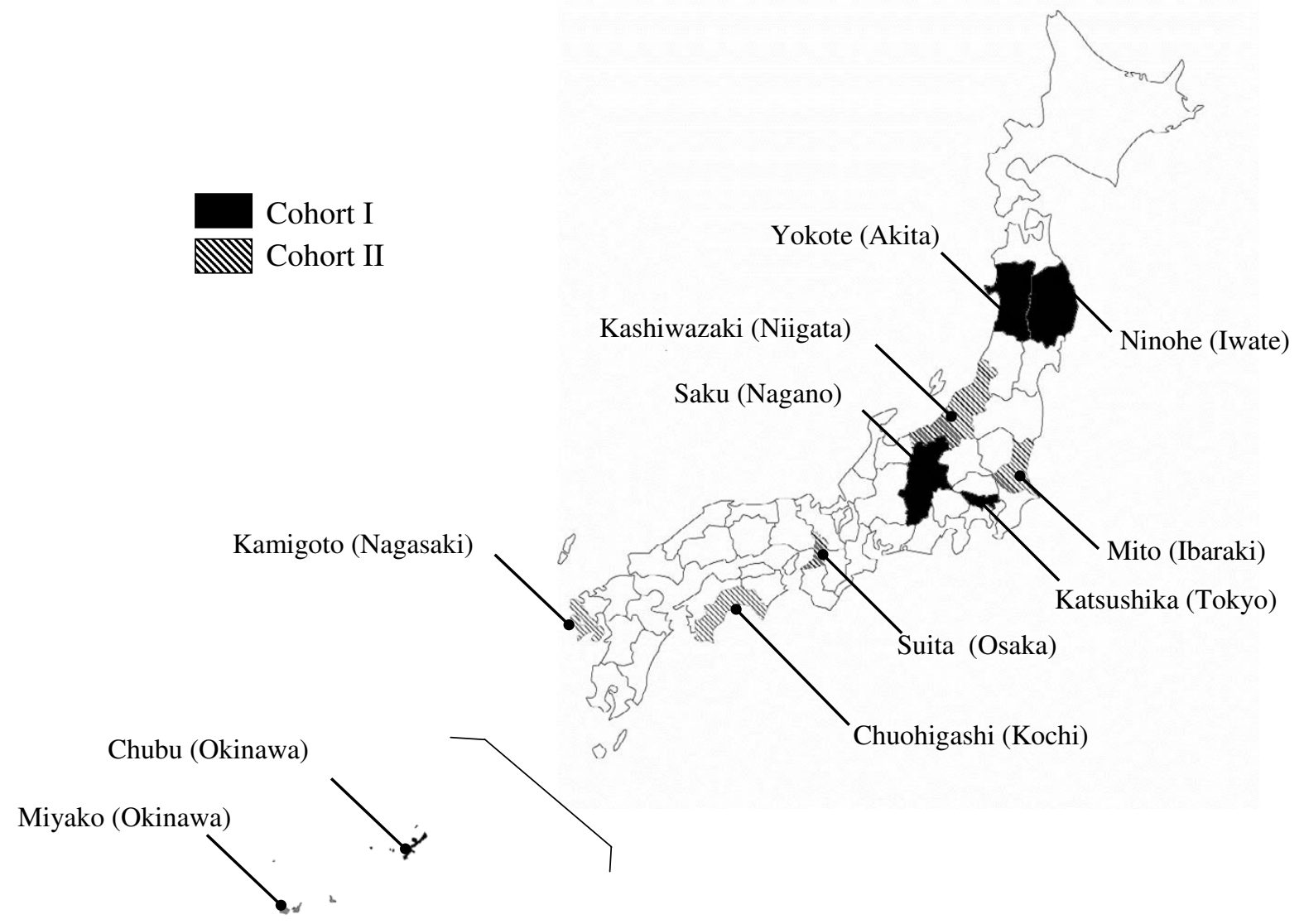

Figure I

Study sites of the JPHC Study.

\section{Introduction}

Owing to their ease of administration and low burden on the subject, the assessment of dietary intake in epidemiological studies is often assessed by means of food frequency questionnaires (FFQs) [1]. The chief limitation of FFQs, however, is that serious errors can occur if foods governing inter-individual differences in intake of certain nutrients are omitted from the list. Folate is particularly prone to such error, because it is derived from a variety of foods of both animal and plant origin, not all of which can be included in an FFQ. Foods that contribute to interindividual differences may fail to be included in food lists, potentially confounding estimation of folate intake by the FFQ.

Another implication of inter-individual variation in the intake of folate or any other nutrient is that such variation may be the underlying determinant of associations between food intake and disease. The preventive effect of certain foods on specific diseases is usually the effect of a particular nutrient contained in the food. Such associations are more likely to be detected when inter-individual differences in intake of the nutrient are larger. Conversely, even if a food contains high levels of a particular nutrient, association will be weak if consumption among individuals is similar. The identification of foods that contribute to inter-individual variation in nutrient intake among the population is therefore an important component of any investigation of nutrients responsible for associations between food intake and disease.

According to the National Nutrition Examination Survey of the United States Population [2] and the National Nutrition Survey in Japan [3], folate intake between the countries is similar among both middle-aged and older 


\section{Cohort I}

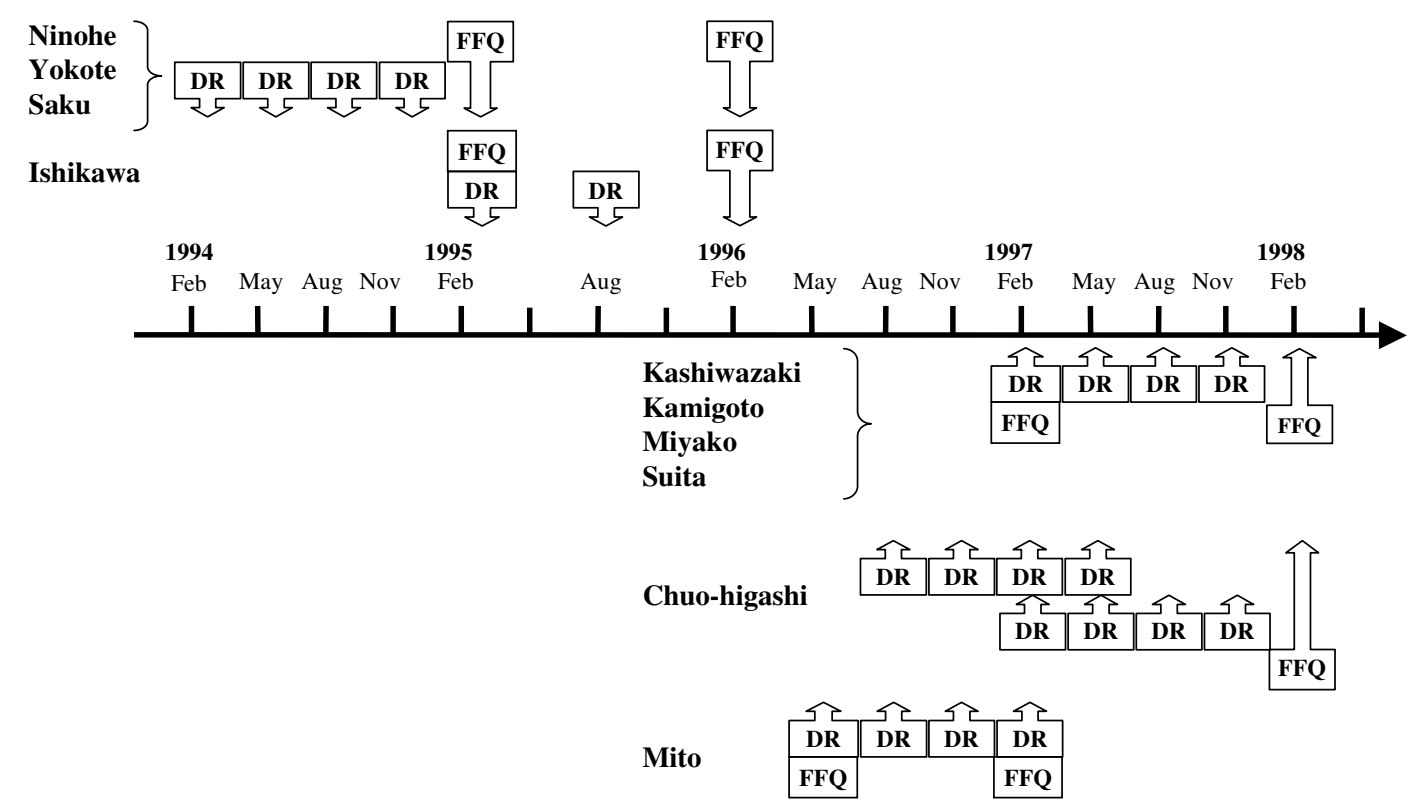

Cohort II

Figure 2

Sequence of data collection for the JPHC FFQ Validation Study.

age groups. Intake among younger groups, however, is much lower in Japan. This trend is presumably due to differences in the foods that contribute to folate intake. Specifically, folate-fortified food and supplements are large contributors to folate intake for individuals in some Western countries, and questionnaires especially designed to assess folate intake include these items [4,5]. Because folate-fortified foods are not available in Japan and supplement consumption is low, however, folate intake is almost exclusively from natural sources. Nevertheless, little is known about those foods that are the main sources of folate intake among Japanese.

A FFQ was developed and validated for the estimation of dietary intake for the JPHC study. Spearman's correlation coefficients (CCs) between serum folate and folate intake estimated by this FFQ using a biomarker as reference was
0.26 in men [6]. In the present report, we evaluated the validity of this FFQ in the population subgroup for which the FFQ was originally developed using dietary records (DRs) as standard. We then attempted to identify foods that most contributed to folate intake, and those responsible for the differences in intake between individuals. We subsequently repeated these analyses in a second subgroup that was independent of the population for which the FFQ was originally developed, i.e., an external population, to assess its generalizability in Japan. The objectives of this study were: 1) to validate this selfadministered FFQ as a means of estimating folate intake, and identify foods that contribute to individual intake and inter-individual variation in folate intake in the population for which the FFQ was developed; and 2) to determine the validity of this FFQ, designed for a study cohort, in estimating the intake of folate and identifying foods 
that predict inter-individual variation in folate in the general Japanese population.

\section{Materials and methods Study Subjects}

Two validation studies of the FFQ were conducted in a subsample of participants in the JPHC Study, a large population-based prospective study that involved medical examination of the study participants. The target population of the JPHC Study consisted of two cohorts, the first started in 1990 (Cohort I) and the second in 1993 (Cohort II). The aim of the cohort study was to investigate the association between various lifestyle factors such as diet and chronic diseases. Despite Japan's small geographical area, considerable regional variation in diet is seen, and study sites were selected to be representative of the whole country. Cohort I was drawn mainly from the northeast part of the country and Cohort II from the southwest (Figure 1). The study design and participants in the entire cohort have been described previously [7].

The present FFQ validation study was conducted in subsamples of Cohort I and Cohort II. The Cohort I study was initiated in February 1995 to validate the FFQ for use in a 5 -year follow-up survey [8], given that it was originally developed based on data from 3-day weighed DRs in a random sample from this Cohort [9], while the Cohort II study was to evaluate the generalizability of the FFQ independent of the population for which it was originally developed [10]. Respective numbers and recruitment areas were 247 volunteers from the Ninohe, Yokote, Saku and Chubu (previously named Ishikawa) public health center areas, and 392 volunteers from Mito, Kashiwazaki, Chuo-higashi, Kamigoto, Miyako and Suita. For the present report, we analyzed the data of the 215 and 350 subjects in Cohorts I and II, respectively, for whom the 28day DR and FFQ data were complete.

\section{Data Collection}

Data collection has been described in detail elsewhere $[8,10]$. In brief, each subject completed two FFQs and 28day DRs (Figure 2). The first FFQ was administered to provide data to compare with the second FFQ as a means of evaluating reproducibility, and the second FFQ was administered to obtain data to compare with the DRs to evaluate its validity. Only data from the second FFQ for validity has been used in this paper.

DRs were collected over 7 consecutive days in each of the 4 seasons, except in Chubu (2 seasons). Local dietitians instructed the subjects to weigh all foods and beverages with the scales and measuring utensils provided, and to record results in a specially designed booklet. The subjects in Cohort I, however, were instructed to use standardized portion sizes for some foods that were difficult to weigh (semi-weighed DRs). The subjects described each food, method of preparation, and the names of the dishes in detail. They also reported all dietary supplements used, if any. At the end of each season, the DRs were reviewed in a standardized manner, and each food was coded by local dietitians.

The self-administered semi-quantitative FFQ consisted of 138 food items and 14 supplementary questions on dietary habits and use of supplements. The validity of the questionnaire in regard to the intake of energy, other nutrients and foods, as well as the use of dietary supplements is described elsewhere [10-13].

Dietary intakes of folate according to the DRs and the FFQ were calculated using the Standardized Tables of Food Composition, 5th ed. [14]. Mean daily intake of folate for the 28 days (14 days in Chubu) was calculated based on the DRs of each subject. Because none of the subjects used folic acid supplementation, dietary supplements were not included in the calculation.

\section{Statistical analysis}

Means and standard deviation of folate intakes from the DRs and FFQ were calculated by sex for Cohort I and Cohort II. Spearman's rank CCs were calculated for crude intake and energy-adjusted intake by the residual method, and were corrected for the attenuating effect of random intra-individual error (deattenuation) in Cohort I subjects to evaluate internal validity in the population for which the FFQ was developed. Deattenuation was done using the following formula: Deattenuated $C C=\sqrt{\left(1+\left(\lambda_{x} / n_{x}\right)\right)}$, where $r$ is the observed correlation, $\lambda_{x}$ is the ratio of intra- to inter-subject variation, and $\mathrm{n}_{\mathrm{x}}$ is number of dietary records for each subject [15]. The same analysis was performed for Cohort II subjects to evaluate external validity

The percentage contribution of each food to total folate intake was computed based on the DRs of Cohort I subjects, and the 20 foods contributing most were listed based on their percentage contribution. Percentage contributions of the same 20 foods in the DRs of Cohort II were calculated and their actual rank of percentage contribution in Cohort II was determined.

Linear regression analysis with stepwise selection was used to identify foods that contributed to inter-individual variation, with folate intake from each food item according to the FFQ of Cohort I used as the explanatory variable, and total folate intake according to the DRs as the response variable. A model (partial) R-square value for the selected food items was computed. Cumulative mean intake from each food item on the list was calculated, and 
Table I: Folate intake ( $\mu$ g/day) assessed by the dietary records and food frequency questionnaire, and their correlation coefficients.

\begin{tabular}{|c|c|c|c|c|c|c|c|c|c|c|}
\hline & \multicolumn{3}{|c|}{$\mathrm{DR}^{\prime}$} & \multicolumn{3}{|c|}{$\mathrm{FFQ}^{2}$} & \multirow[b]{2}{*}{$\begin{array}{l}\% \text { difference } \\
\text { of mean }\end{array}$} & \multicolumn{3}{|c|}{ Spearman correlation } \\
\hline & Mean \pm SD & Median & Range & Mean \pm SD & Median & Range & & Crude & $\begin{array}{l}\text { Energy- } \\
\text { adjusted }^{3}\end{array}$ & Deattenuated \\
\hline \multicolumn{11}{|l|}{ Cohort I } \\
\hline Men $(n=102)$ & $425 \pm 103$ & 427 & $210-735$ & $473 \pm 231$ & 444 & $119-1807$ & 11 & 0.49 & 0.40 & 0.57 \\
\hline Women $(n=113)$ & $389 \pm 106$ & 380 & $153-667$ & $476 \pm 287$ & 419 & $146-1978$ & 22 & 0.29 & 0.35 & 0.47 \\
\hline \multicolumn{11}{|l|}{ Cohort II } \\
\hline Men $(n=174)$ & $467 \pm 156$ & 443 & $197-1280$ & $421 \pm 190$ & 370 & $85-1178$ & -10 & 0.33 & 0.50 & 0.63 \\
\hline Women $(n=176)$ & $426 \pm 112$ & 417 & $198-980$ & $454 \pm 237$ & 397 & $4-1498$ & 7 & 0.42 & 0.48 & 0.63 \\
\hline
\end{tabular}

compared to total intake according to the DRs by Spearman's CCs to evaluate validity. Cumulative intake from the same food items in the Cohort II subjects and their CCs from the DR data were calculated to evaluate external validity.

\section{Results}

Daily folate intake as assessed by DRs and FFQ as well as the Spearman's rank CCs between the two measurements by cohort group and sex are shown in Table 1. Mean daily intake of folate based on the FFQ in Cohort I was significantly overestimated compared to the DR data. Both crude and adjusted CCs were higher in men than women in Cohort I but were similar in Cohort II (Table 1).

The 20 foods that made the greatest contribution to total folate according to the DR in Cohort I are listed in Table 2. The list consists of various foods, mainly from plant sources such as vegetables, with spinach making the highest contribution followed by rice, green tea, cabbage, eggs and beer. These 20 foods contributed 55.2\% of total intake in men and $52.9 \%$ in women. The contribution of the same 20 foods to folate intake in Cohort II subjects was $44.9 \%$ for men and $43.2 \%$ for women. Gyokuro, a type of green tea, made the second highest contribution in Cohort II, but was not among the 20 in Cohort I. Other food items with the highest contribution in Cohort II but not Cohort I were kamairi-cha (pan-fried green tea), bread, tomatoes, and pumpkins in both sexes; purple laver in men; and sweet potatoes and komatsuna (a green leafy vegetable) in women. When both kinds of green tea were excluded, however, these foods accounted for only $4.6 \%$ of total intake in men and $6.2 \%$ in women.

The foods that best predicted inter-individual variation in dietary folate and the validity (correlation coefficients) of folate intake based on those foods are shown in Table 3. A total of 33 foods are listed with the cumulative R-square value of 0.59 . The food that best predicted variation of intake was green tea, which contributed $12-15 \%$ of total intake. No other food predictive of variation contributed more than $1 \%$ of total folate intake. The cumulative folate intake from the 33 foods contributed approximately $30 \%$ of total intake in both men and women. The CC of intake from the 33 foods in the internal population (Cohort I) was 0.46 in men and 0.28 in women (indicated as "internal" in Table 3), and had approximately the same level of validity as the data from the full 138-food FFQ.

When the same 33-food list was used to compute intake in the external population (Cohort II), the cumulative folate intake contribution was again 30\% (indicated as "external" in Table 3), and CC was 0.30 in men and 0.35 in women, showing approximately the same level of validity as in the internal population.

\section{Discussion}

In this study, we evaluated the validity of a FFQ as a means of estimating dietary folate intake in the population for which the FFQ was originally developed. We also attempted to identify foods that differentiated the level of folate intake in individuals by stepwise regression, and tested the validity of assessing folate intake based on the intake of these foods. The results were also cross-validated in an independent population to evaluate generalizability.

Validity of the FFQ in estimating folate intake was moderate in both the internal and external populations. In previous studies, the validity of questionnaires in estimating energy-adjusted dietary folate intake varied from 0.2 to 0.6 , depending on the study population [15-21]. In studies that reported intake from the diet and from dietary supplements separately, CC was 6-21\% higher for folate intake that included supplements than for intake from diet alone. Although none of the subjects used supple- 
Table 2: Foods that contribute to folate intake and their cumulative percentage contribution to total intake as assessed by dietary records.

\begin{tabular}{|c|c|c|c|c|c|c|c|c|c|}
\hline \multirow{2}{*}{$\begin{array}{l}\text { Men } \\
\text { Food item }\end{array}$} & \multicolumn{2}{|c|}{ Cohort I } & \multicolumn{2}{|c|}{ Cohort II } & \multirow{2}{*}{$\begin{array}{l}\text { Women } \\
\text { Food items }\end{array}$} & \multicolumn{2}{|c|}{ Cohort I } & \multicolumn{2}{|c|}{ Cohort II } \\
\hline & Rank' & $\%$ & Rank $^{2}$ & $\%$ & & Rank' & $\%$ & Rank $^{2}$ & $\%$ \\
\hline Spinach, leaves & 1 & 6.5 & 3 & 5.4 & Spinach, leaves & 1 & 7.1 & 3 & 5.6 \\
\hline Well-milled rice & 2 & 6.4 & 4 & 5.0 & Green tea, sencha, infusion & 2 & 6.1 & I & 10.1 \\
\hline Green tea, sencha, infusion & 3 & 5.6 & I & 9.1 & Cabbage, head & 3 & 4.7 & 5 & 3.4 \\
\hline Cabbage, head & 4 & 4.9 & 5 & 3.6 & Well-milled rice & 4 & 4.5 & 4 & 3.6 \\
\hline Chicken eggs, whole & 5 & 3.8 & 6 & 3.6 & Chicken eggs, whole & 5 & 3.5 & 6 & 3.1 \\
\hline Beer & 6 & 3.3 & 7 & 3.0 & Aspargus, shoots & 6 & 2.8 & 36 & 0.7 \\
\hline Radish, root with skin & 7 & 2.6 & 8 & 2.5 & Chiken offal, liver & 7 & 2.5 & 15 & 1.2 \\
\hline Pork offal, liver & 8 & 2.4 & 35 & 0.7 & Radish, root with skin & 8 & 2.5 & 7 & 2.4 \\
\hline Aspargus, shoots & 9 & 2.3 & 34 & 0.7 & Bracken, young shoots & 9 & 1.9 & 72 & 0.3 \\
\hline $\begin{array}{l}\text { Natto, itohiki-natto (whole fermented } \\
\text { using Bacillus natto) }\end{array}$ & 10 & 2.0 & 13 & 1.4 & $\begin{array}{l}\text { Natto, Itohiki-natto (Whole fermented } \\
\text { using Bacillus natto) }\end{array}$ & 10 & 1.9 & 10 & 1.7 \\
\hline Miso, rice- koji miso, dark yellow type & 11 & 1.9 & 46 & 0.5 & Broccoli, florets & 11 & 1.8 & 8 & 2.0 \\
\hline Chiken offal, liver & 12 & 1.8 & 12 & 1.4 & Miso, rice- koji miso, dark yellow type & 12 & 1.8 & 55 & 0.4 \\
\hline Chinese cabbage, head & 13 & 1.8 & 11 & 1.7 & Chinese cabbage, head & 13 & 1.7 & 11 & 1.6 \\
\hline Bracken, young shoots & 14 & 1.6 & 67 & 0.3 & Ordinary liquid milk & 14 & 1.5 & 20 & I.I \\
\hline Broccoli, florets & 15 & 1.6 & 9 & 1.8 & $\begin{array}{l}\text { Shoyu: soy sauce, Koikuchi-shoyu } \\
\text { (Common type) }\end{array}$ & 15 & 1.5 & 23 & 1.0 \\
\hline $\begin{array}{l}\text { Shoyu: soy sauce, Koikuchi-shoyu } \\
\text { (Common type) }\end{array}$ & 16 & 1.6 & 17 & I.I & Head letucce, crisp type, head & 16 & 1.5 & 22 & I.I \\
\hline $\begin{array}{l}\text { Carrots, European type, root with } \\
\text { skin }\end{array}$ & 17 & 1.4 & 16 & I.I & Purple laver, toasted & 17 & 1.5 & 18 & I.I \\
\hline Potatoes, tuber & 18 & 1.3 & 23 & 0.9 & Pork offal, liver & 18 & 1.4 & 34 & 0.7 \\
\hline Head lettuce, crisp type, head & 19 & 1.3 & 22 & 1.0 & $\begin{array}{l}\text { Carrots, European type, root with } \\
\text { skin }\end{array}$ & 19 & 1.4 & 17 & I.I \\
\hline Leaf mustard, leaves & 20 & 1.2 & 75 & 0.2 & Potatoes, tuber & 20 & 1.3 & 26 & 0.9 \\
\hline Total & & 55.2 & & 44.9 & & & 52.9 & & 43.1 \\
\hline
\end{tabular}

I Food items are listed in order of \% contribution to total folate intake based on dietary records of Cohort I (by rank in Cohort I).

2 Rank of \% contribution to total folate intake determined on the basis of the dietary records of Cohort II.

ments that contained folic acid, which had only just become available at the time of the study, the validity of our FFQ in estimating folate from the diet was relatively high, probably because the dietary folate intake of our subjects was as high as that of supplement users in some of the previously cited studies.

Although the largest proportion of folate intake was from vegetables, these did not necessarily explain the differences in intake between individuals. For example, spinach, which is very rich in folate and was one of the highest contributors to mean folate intake, could not explain inter-individual variation because it was consumed by almost every subject. In contrast, green tea contributed greatly to both individual intake and to inter-individual variation, probably because consumption was strongly dependent on individual preference. Although the analysis provided us with information about foods that predicted inter-individual variation in folate intake, some foods which had a moderate partial R-square value con- tributed less than $0.1 \%$ to total folate intake, such as luncheon meat, ham, and so on. These may have been selected by chance alone. In this kind of analysis, even unimportant contributors to the cumulative R-square value may be statistically significant, but can nevertheless be ignored [1]. In any case, it is noteworthy that individuals could be ranked by folate intake based on only 33 foods, with the same level of validity as with the long FFQ.

Any analysis of the possible effects of folate intake on disease also requires analysis of the effect of food items which contribute to total intake and inter-individual variation of folate. It is of great research interest to determine whether the association between food intake and disease is the result of folate intake. For example, we might hypothesize that folate intake may help explain the protective effect of green tea on gastric cancer described in the recent report of the JPHC study [22]. The mechanism of carcinogenesis through DNA instability and methylation abnormalities as a result of folate deficiency has been 
Table 3: Foods most predictive of inter-individual variation in dietary folate, and their correlation coefficients with intake from DR.

\begin{tabular}{|c|c|c|c|c|c|c|c|c|c|c|c|c|c|c|}
\hline \multirow[t]{4}{*}{ Foods selected by regression analysis ${ }^{\prime}$} & \multicolumn{2}{|c|}{ Male and female } & \multicolumn{6}{|c|}{ Male } & \multicolumn{6}{|c|}{ Female } \\
\hline & \multirow{3}{*}{$\begin{array}{c}\text { Partial } \\
\text { R-Square }\end{array}$} & \multirow{3}{*}{$\begin{array}{l}\text { Cumulative } \\
\text { R-Square' }^{\text {I }}\end{array}$} & \multicolumn{3}{|c|}{ Cohort I (internal) } & \multicolumn{3}{|c|}{ Cohort II (external) } & \multicolumn{3}{|c|}{ Cohort I (internal) } & \multicolumn{3}{|c|}{ Cohort II (external) } \\
\hline & & & \multicolumn{2}{|c|}{$\begin{array}{l}\text { Cumulative } \\
\text { mean intake }\end{array}$} & \multirow[t]{2}{*}{$\begin{array}{l}\text { Spearman } \\
\text { correlation }\end{array}$} & \multicolumn{2}{|c|}{$\begin{array}{l}\text { Cumulative } \\
\text { mean intake }\end{array}$} & \multirow[t]{2}{*}{$\begin{array}{l}\text { Spearman } \\
\text { correlation } \\
\text { corrat }\end{array}$} & \multicolumn{2}{|c|}{$\begin{array}{l}\text { Cumulative } \\
\text { mean intake }\end{array}$} & \multirow[t]{2}{*}{$\begin{array}{l}\text { Spearman } \\
\text { correlation }\end{array}$} & \multicolumn{2}{|c|}{$\begin{array}{l}\text { Cumulative } \\
\text { mean intake }\end{array}$} & \multirow[t]{2}{*}{$\begin{array}{l}\text { Spearman } \\
\text { correlation }\end{array}$} \\
\hline & & & $\mu g /$ day & $(\%)^{2}$ & & $\mu g /$ day & $(\%)^{2}$ & & $\mu g /$ day & $(\%)^{2}$ & & $\mu g /$ day & $(\%)^{2}$ & \\
\hline Green tea (sencha) & 0.096 & 0.096 & 72 & $(15.3)$ & 0.31 & 55 & $(13.0)$ & 0.28 & 55 & $(11.6)$ & 0.17 & 66 & $(14.6)$ & 0.25 \\
\hline Dried small fish & 0.070 & 0.166 & 73 & $(15.4)$ & 0.33 & 55 & $(13.1)$ & 0.27 & 56 & (II.7) & 0.19 & 67 & $(14.7)$ & 0.26 \\
\hline Horse mackerel, sardine & 0.039 & 0.204 & 74 & $(15.7)$ & 0.37 & 57 & $(13.5)$ & 0.27 & 57 & $(12.0)$ & 0.20 & 68 & $(15.0)$ & 0.24 \\
\hline Cake & 0.031 & 0.236 & 74 & $(15.7)$ & 0.37 & 57 & $(13.6)$ & 0.27 & 58 & $(12.1)$ & 0.19 & 69 & $(15.1)$ & 0.24 \\
\hline Miso soup & 0.030 & 0.266 & 84 & $(17.8)$ & 0.37 & 62 & $(14.8)$ & 0.28 & 66 & $(13.8)$ & 0.24 & 73 & $(16.1)$ & 0.27 \\
\hline Luncheon Meat & 0.032 & 0.298 & 84 & $(17.8)$ & 0.38 & 62 & $(14.8)$ & 0.28 & 66 & $(13.8)$ & 0.24 & 73 & $(16.1)$ & 0.27 \\
\hline Ham, loin & 0.022 & 0.320 & 84 & $(17.8)$ & 0.38 & 62 & $(14.8)$ & 0.29 & 66 & (13.8) & 0.24 & 73 & $(16.1)$ & 0.27 \\
\hline Cream for coffee & 0.014 & 0.335 & 85 & $(17.9)$ & 0.37 & 63 & $(14.9)$ & 0.28 & 66 & (13.9) & 0.24 & 74 & $(16.2)$ & 0.27 \\
\hline Stewed pork, Western style & 0.012 & 0.346 & 85 & $(17.9)$ & 0.37 & 63 & $(15.0)$ & 0.28 & 66 & $(14.0)$ & 0.24 & 74 & (16.2) & 0.27 \\
\hline Mayonnaise & 0.011 & 0.357 & 85 & $(17.9)$ & 0.37 & 63 & $(15.0)$ & 0.28 & 66 & $(14.0)$ & 0.24 & 74 & $(16.2)$ & 0.27 \\
\hline Worcester sauce & 0.013 & 0.370 & 85 & $(17.9)$ & 0.37 & 63 & $(15.0)$ & 0.28 & 66 & $(14.0)$ & 0.24 & 74 & $(16.2)$ & 0.27 \\
\hline Kamaboko (fish paste product) & 0.014 & 0.384 & 85 & $(18.0)$ & 0.37 & 63 & $(15.0)$ & 0.28 & 67 & $(14.0)$ & 0.24 & 74 & $(16.3)$ & 0.27 \\
\hline Lettuce & 0.011 & 0.395 & 86 & $(18.3)$ & 0.37 & 64 & $(15.3)$ & 0.30 & 68 & $(14.3)$ & 0.25 & 75 & $(16.5)$ & 0.27 \\
\hline Bean sprouts & 0.015 & 0.410 & 88 & $(18.7)$ & 0.37 & 66 & $(15.7)$ & 0.29 & 71 & (14.9) & 0.23 & 77 & (16.9) & 0.26 \\
\hline Peaches & 0.017 & 0.427 & 89 & $(18.7)$ & 0.38 & 66 & $(15.8)$ & 0.29 & 71 & $(14.9)$ & 0.23 & 77 & $(17.0)$ & 0.26 \\
\hline Sausage, Wieners & 0.011 & 0.437 & 89 & $(18.7)$ & 0.38 & 66 & $(15.8)$ & 0.29 & 71 & $(14.9)$ & 0.23 & 77 & $(17.0)$ & 0.26 \\
\hline Chocolate & 0.009 & 0.446 & 89 & $(18.8)$ & 0.38 & 67 & $(15.9)$ & 0.29 & 71 & $(15.0)$ & 0.23 & 78 & $(17.1)$ & 0.26 \\
\hline Octopus & 0.008 & 0.455 & 89 & $(18.8)$ & 0.38 & 67 & $(15.9)$ & 0.29 & 71 & $(15.0)$ & 0.23 & 78 & $(17.1)$ & 0.26 \\
\hline Salted fish & 0.008 & 0.463 & 90 & $(19.1)$ & 0.38 & 68 & $(16.0)$ & 0.30 & 73 & (I5.2) & 0.23 & 78 & (17.2) & 0.26 \\
\hline Apples & 0.010 & 0.473 & 92 & (19.5) & 0.38 & 69 & $(16.3)$ & 0.31 & 75 & $(15.8)$ & 0.24 & 80 & $(17.6)$ & 0.26 \\
\hline Sweet pepper & 0.012 & 0.485 & 94 & $(19.8)$ & 0.39 & 70 & $(16.6)$ & 0.31 & 77 & $(16.1)$ & 0.26 & 81 & (17.9) & 0.27 \\
\hline Udon & 0.011 & 0.496 & 95 & $(20.0)$ & 0.39 & 71 & $(17.0)$ & 0.30 & 78 & $(16.3)$ & 0.25 & 82 & $(18.1)$ & 0.27 \\
\hline Grilled chicken & 0.014 & 0.510 & 95 & $(20.1)$ & 0.39 & 72 & $(17.1)$ & 0.30 & 78 & $(16.4)$ & 0.25 & 83 & $(18.2)$ & 0.27 \\
\hline Pickled plums & 0.009 & 0.519 & 95 & $(20.1)$ & 0.39 & 72 & $(17.1)$ & 0.30 & 78 & (16.4) & 0.25 & 83 & $(18.2)$ & 0.27 \\
\hline Papaya & 0.009 & 0.528 & 96 & $(20.2)$ & 0.39 & 73 & (17.3) & 0.29 & 79 & $(16.5)$ & 0.25 & 83 & $(18.4)$ & 0.27 \\
\hline Black tea & 0.007 & 0.536 & 96 & $(20.4)$ & 0.39 & 73 & $(17.4)$ & 0.30 & 79 & $(16.7)$ & 0.24 & 84 & $(18.5)$ & 0.28 \\
\hline Green tea (bancha, genmaicha) & 0.007 & 0.542 & 105 & $(22.1)$ & 0.42 & 83 & $(19.8)$ & 0.33 & 88 & $(18.6)$ & 0.25 & 95 & $(21.0)$ & 0.35 \\
\hline Chicken liver & 0.007 & 0.550 & 122 & $(25.8)$ & 0.45 & 98 & $(23.2)$ & 0.32 & 101 & $(21.2)$ & 0.28 & 107 & $(23.6)$ & 0.34 \\
\hline Bananas & 0.008 & 0.557 & 126 & $(26.6)$ & 0.46 & 101 & $(24.1)$ & 0.32 & 104 & $(21.9)$ & 0.27 & 111 & $(24.3)$ & 0.34 \\
\hline Rice mixed with other grains & 0.005 & 0.562 & 128 & $(27.1)$ & 0.45 & 103 & $(24.5)$ & 0.33 & 107 & $(22.5)$ & 0.27 & 112 & $(24.8)$ & 0.34 \\
\hline Well-milled rice & 0.011 & 0.573 & 152 & $(32.2)$ & 0.49 & 124 & $(29.5)$ & 0.30 & 125 & $(26.2)$ & 0.29 & 128 & $(28.3)$ & 0.34 \\
\hline Yushi-dofu & 0.006 & 0.579 & 153 & $(32.3)$ & 0.49 & 125 & $(29.6)$ & 0.30 & 125 & $(26.3)$ & 0.29 & 129 & $(28.4)$ & 0.34 \\
\hline Bitter gourds & 0.011 & 0.590 & 158 & (33.3) & 0.46 & 128 & $(30.5)$ & 0.30 & 130 & $(27.2)$ & 0.28 & 132 & $(29.1)$ & 0.35 \\
\hline
\end{tabular}

I Foods were selected by stepwise regression analysis using data from the food frequency questionnaire of Cohort I men and women. Partial and cumulative R-Square values were calculated in the process of performing the regression analysis.

2 Percent of total folate according to the food frequency questionnaire.

${ }^{3}$ Spearman's correlation coefficients between cumulative intake and total intake based on dietary records 
studied in animal and in vitro studies [23-25], and an association between folate and gastric cancer has been reported in a number of case-control studies [26-29]. Other prospective studies, however, have failed to show a consistent association between green tea and gastric cancer [30-32]. We speculate that the association was strong in the JPHC population owing to the large contribution of green tea to the variation in folate intake, which was not seen in the other populations.

One of the strengths of our study is the precision of the reference data. The ratio of intra- to inter-individual variation in our data was somewhat higher (1.9-4.8) than in several studies in Western countries $[33,34]$. When intraindividual variation is larger, an increased number of dietary assessment days is required to obtain a valid standard. Although intra-individual variation among our subjects was high, we had more than a sufficient numbers of days (28 days) of data to represent the true intake of the individuals, because the number of DR days needed to estimate true intake within $20 \%$ of the true mean with our data was only about 17 to 19 days according to our analysis. By comparison, the greatest number of days of dietary assessment used as standard in previous studies was 14 days [35].

In addition, our analysis is unique because we used regression analysis to identify the foods most predictive for inter-individual variation in dietary folate, and then evaluated both the internal and external validity of the intake of those foods. It is important to test external validity, because there is no assurance that explanatory variables selected by regression analysis are valid in an external population [1]. To our knowledge, this is the first study to attempt to identify foods that contribute to inter-individual variation of folate intake in Japan, where folate intake is almost exclusively from natural sources. We developed a list of foods that contribute to inter-individual variation in folate intake in the population for which FFQ was originally developed, and tested the generalizability of the results to an external population. The two populations covered various geographic areas throughout Japan. Our results imply the possibility that a shorter questionnaire which specifically targets folate intake in Japanese populations can be developed.

One limitation of our study is that because the subjects needed to be highly motivated to complete the 28-day DRs, they were not a randomly selected sample. Mean folate intake based on DRs was slightly higher than in the entire cohort, probably because the validation study subjects were likely more health conscious and consumed more vegetables. If all subjects had consumed a similar amount of certain foods, inter-individual variation in the food might have been falsely low. The generalizability of questionnaire results needs to be established with care.

\section{Conclusion}

Our FFQ is valid for estimating folate intake and is generalizable to the Japanese population. Although some foods such as spinach, rice and cabbage contributed more to total intake of folate, they did not necessarily contribute to inter-individual variation. Validity of the estimation of folate intake based on intake of the 33 foods that most contributed to inter-individual variation was about the same as that based on the original 138-food FFQ. Although folate is contained in a wide variety of foods, 33 foods in the FFQ were sufficient to account for the interindividual variation of intake and ranking of individuals' intake in Japan. We concluded that the FFQ with 138 foods was valid for the estimation of folate intake, and that the FFQ with 33 foods might be useful for estimating inter-individual variation and the ranking of individual folate intake.

\section{Competing interests}

The author(s) declare that they have no competing interests.

\section{List of Abbreviations}

FFQ: food frequency questionnaire

DR: dietary record

CC: correlation coefficients

JPHC Study: Japan Public Health Center-based prospective Study

\section{Authors' contributions}

JI performed the data analysis and drafted the manuscript

SY participated in the design of the study, coordinated the study and helped with analysis and with the preparation of the manuscript

HI helped with analysis and with the preparation of the manuscript

MI helped with analysis and with the preparation of the manuscript

ST participated in the design of the study and helped to draft the manuscript. He was principal investigator of the JPHC Study

All authors have read and approved the final manuscript. 


\section{Acknowledgements}

This study was supported by grants-in-aid for Cancer Research and for the Third-Term Comprehensive Ten-Year Strategy for Cancer Control from the Ministry of Health, Labor and Welfare of Japan and for Scientific Research from the Ministry of Education, Culture, Sports, Science and Technology of Japan. Junko Ishihara is an Awardee of Research Resident Fellowship from the foundation of Promotion of Cancer Research (Japan) for the 3rd Term Comprehensive 10-Year-Strategy for Cancer Control.

The authors wish to express their appreciation to the local staff in each study area, especially to the local dietitians for their efforts in conducting the dietary survey. The investigators in the validation study of the selfadministered food frequency questionnaire in the JPHC Study (the JPHC FFQ Validation Study Group) and their affiliations at the time of the study were: S. Tsugane, S. Sasaki, and M. Kobayashi, Epidemiology and Biostatistics Division, National Cancer Center Research Institute East, Kashiwa; T. Sobue, S. Yamamoto, and J. Ishihara, Cancer Information and Epidemiology Division, National Cancer Center Research Institute, Tokyo; M. Akabane, Y. litoi, Y. Iwase, and T. Takahashi, Tokyo University of Agriculture, Tokyo; K. Hasegawa, and T. Kawabata, Kagawa Nutrition University, Sakado; Y. Tsubono, Tohoku University, Sendai; H. Iso, Tsukuba University, Tsukuba; S. Karita, Teikyo University, Tokyo; the late M. Yamaguchi, and Y. Matsumura, National Institute of Health and Nutrition, Tokyo.

\section{References}

I. Willett WC: Nutrition Epidemiology. second edition. Oxford, UK, Oxford University Press; 1998.

2. Ervin RB, Wright JD, Wang CY, Kennedy-Stephenson J: Dietary intake of selected vitamins for the United States Population: 1999-2000. In Advance data from vital and health statistics Hyattsville, Maryland, National Center for Health Statistics; 2004:2004-I 250.

3. The Study Circle for Health and Nutrition Information: Kokumin Eiyo no Genjou (Results of National Nutrition Survey in Japan, 2002, Ministry of Health, Labour and Welfare, Japan). Tokyo, Japan, Daiichi Shuppan Publishers. (in Japanese); 2004.

4. Pufulete M, Emery PW, Nelson M, Sanders TA: Validation of a short food frequency questionnaire to assess folate intake. British Journal of Nutrition 2002, 87:383-390.

5. Yen J, Zoumas-Morse C, Pakiz B, Rock CL: Folate intake assessment: validation of a new approach. J Am Diet Assoc 2003, 103:991-1000.

6. Iso H, Moriyama Y, Yoshino K, Sasaki S, Ishihara J: Validity of a selfadministered food frequency questionnaire used in the 5year follow-up survey for the JPHC Study to assess folate, vitamin B6, B 12 intake: comparison with dietary records and blood level. J Epidemiol 2003, I3(I Suppl):S98-I0I.

7. Watanabe S, Tsugane S, Sobue T, Konishi M, Baba S, for the JPHC Study group: Study design and organization of JPHC Study. J Epidemiol 200I, II (6 Suppl):S3-S7.

8. Tsugane S, Kobayashi M, Sasaki S, Tsubono Y, M A: Validity and reproducibility of a self-administered food frequency questionnaire in the JPHC Study Cohort I: study design, conduct and participant profiles. J Epidemiol 2003, I 3(I Suppl):S2-S I2.

9. Tsubono $Y$, Takamori S, Kobayashi M, Takahashi T, Iwase $Y$, litoi $Y$, Akabane M, Yamaguchi M, Tsugane S: A data-based approach for designing a semiquantitative food frequency questionnaire for a population-based prospective study in Japan. J Epidemiol 1996, 6:45-53

10. Ishihara J, Sobue T, Yamamoto S, Yoshimi I, Sasaki S, Kobayashi M, Takahashi T, litoi Y, Akabane M, Tsugane S: Validity and reproducibility of a self-administered food frequency questionnaire used in the 5-year follow-up survey of the JPHC Study Cohort II: study design, participant profile and results in comparison with Cohort I. J Epidemiol 2003, I3(I Suppl):SI34-SI47.

II. Tsugane S, Kobayashi M, Sasaki S: Validity of a self-administered food frequency questionnaire used in the 5-year follow-up survey of the JPHC Study Cohort I: comparison with dietary records for main nutrients. I Epidemiol 2003, I3(I Suppl):S5I-S56.
12. Ishihara J, Sobue T, Yamamoto S, Sasaki S, Akabane M, Tsugane S: Validity and reproducibility of a self-administered questionnaire to determine dietary supplement users among Japanese. European Journal of Clinical Nutrition 200I, 55:360-365.

13. Sasaki S, Kobayashi M, Tsugane S: Validity of a self-administered food frequency questionnaire used in the 5-year follow-up survey of the JPHC Study Cohort I: comparison with dietary records for food groups. J Epidemiol 2003, I3(I Suppl):S57-S63.

14. Science and Technology Agency: Standard Tables of Food Composition in Japan, the fifth revised edition. Tokyo, Printing Bureau, Ministry of Finance; 2002.

15. Kabagambe EK, Baylin A, Allan DA, Siles X, Spiegelman D, Campos H: Application of the method of triads to evaluate the performance of food frequency questionnaires and biomarkers as indicators of long-term dietary intake. American Journal of Epidemiology 200।, 154: I I26-II35.

16. Flagg EW, Coates RJ, Calle EE, Potischman N, Thun MJ: Validation of the American Cancer Society Cancer Prevention Study II Nutrition Survey Cohort Food Frequency Questionnaire. Epidemiology 2000, II:462-468.

17. Rimm EB, Giovannucci EL, Stampfer MJ, Colditz GA, Litin LB, Willett WC: Reproducibility and validity of an expanded self-administered semiquantitative food frequency questionnaire among male health professionals. American Journal of Epidemiology 1992, 135: I| | 4-1| 26.

18. Munger R, Folsom A, Kushi L, Kaye S, Sellers T: Dietary assessment of older lowa women with a food frequency questionnaire: nutrient intake, reproducibility, and comparison with 24-hour dietary recall interviews. Am J Epidemiol 1992, 136: 192-200.

19. Feskanich D, Marshall J, Rimm EB, Litin LB, Willett WC: Simulated validation of a brief food frequency questionnaire. Annals of Epidemiology 1994, 4:18I-187.

20. Rockett HR, Breitenbach M, Frazier AL, Witschi J, Wolf AM, Field AE, Colditz GA: Validation of a youth/adolescent food frequency questionnaire. Preventive Medicine 1997, 26:808-816.

21. Messerer M, Johansson SE, Wolk A: The validity of questionnairebased micronutrient intake estimates is increased by including dietary supplement use in Swedish men. Journal of Nutrition 2004, 134:1800-1805.

22. Sasazuki S, Inoue M, Hanaoka T, Yamamoto S, Sobue T, Tsugane S: Green Tea Consumption and Subsequent Risk of Gastric Cancer by Subsite: The JPHC Study. Cancer Causes Control 2004, | 5:483-49|.

23. Steinmetz KA, Potter JD: Vegetables, fruits and cancer. II. Mechanisms. Cancer Causes and Control 1991, 2:427-442.

24. Kim Y, Pogribny I, Basnakian A, Miller J, Selhub J, James S, Mason J: Folate deficiency in rats induces DNA strand breaks and hypomethylation within the $\mathrm{p} 53$ tumor suppressor gene. Am J Clin Nutr 1997, 65:46-52.

25. Jacob RA, Gretz DM, Taylor PC, James SJ, Pogribny IP, Miller BJ, Henning SM, Swendseid ME: Moderate folate depletion increases plasma homocysteine and decreases lymphocyte DNA methylation in postmenopausal women. 1998, 1 28: I 204- 1212.

26. La Vecchia C, Ferraroni M, D'Avanzo B, Decarli A, S F: Selected micronutrient intake and the risk of gastric cancer. Cancer Epidemiol Biomarkers Prev 1994, 3:393-398.

27. Gonzalez CA, Riboli E, Badosa J, Batiste E, Cardona T, Pita S, Sanz JM, Torrent M, Agudo A: Nutritional factors and gastric cancer in Spain. American Journal of Epidemiology 1994, 139:466-473.

28. Nomura AM, Hankin JH, Kolonel LN, Wilkens LR, Goodman MT, Stemmermann GN: Case-control study of diet and other risk factors for gastric cancer in Hawaii (United States). Cancer Causes and Control 2003, 14:547-558.

29. Mayne ST, Risch HA, Dubrow R, Chow WH, Gammon MD, Vaughan TL, Farrow DC, Schoenberg JB, Stanford JL, Ahsan H, West AB, Rotterdam H, Blot WJ, Fraumeni JFJ: Nutrient intake and risk of subtypes of esophageal and gastric cancer. Cancer Epidemiol Biomarkers Prev 2001, 10:1055-1062.

30. Koizumi Y, Tsubono Y, Nakaya N, Nishino Y, Shibuya D, Matsuoka H, Tsuji I: No association between green tea and the risk of gastric cancer: pooled analysis of two prospective studies in Japan. Cancer Epidemiol Biomarkers Prev 2003, I 2:472-473.

31. Hoshiyama Y, Kawaguchi T, Miura Y, Mizoue T, Tokui N, Yatsuya H, Sakata K, Kondo T, Kikuchi S, Toyoshima H, Hayakawa N, Tamakoshi A, Ohno Y, Yoshimura T, Japan Collaborative Cohort Study Group: 
A prospective study of stomach cancer death in relation to green tea consumption in Japan. British Journal of Cancer 2002, 87:309-313.

32. Tsubono $\mathrm{Y}$, Nishino $\mathrm{Y}$, Komatsu S, Hsieh CC, Kanemura S, Tsuji I, Nakatsuka H, Fukao A, Satoh H, Hisamichi S: Green tea and the risk of gastric cancer in Japan. New England Journal of Medicine 200I, 344:632-636.

33. Sempos CT, Johnson NE, Smith EL, Gilligan C: Effects of intraindividual and interindividual variation in repeated dietary records. American Journal of Epidemiology 1985, I21: | 20- I30.

34. Hunt WC, Leonard AG, Garry PJ, Goodwin JS: Components of variation in dietary data for an elderly population. Nutrition Research 1983, 3:433-444.

35. Messerer M, Johansson SE, Wolk A: Sociodemographic and health behaviour factors among dietary supplement and natural remedy users. European Journal of Clinical Nutrition 200I, 55: I 104-1। I0. 